\title{
IMPROVEMENT OF QUALITY AND COOKING CHARACTERISTICS OF BROWN RICE USING ULTRASONIC TREATMENT
}

\author{
Ragab K. A. E.*
}

\begin{abstract}
Ultrasonic technology has promising potentials in terms of improving the sensory characteristics, cooking and nutritional properties of brown rice. The rice samples (variety M202) were treated with an ultrasonic system with frequencies of 16 and $20 \mathrm{kHz}$ for four exposure durations, 15, 30, 45 , and 60 min at water temperature of 25 and $40^{\circ} \mathrm{C}$. Optimum cooking time, water uptake ratio, length expansion ratio and volume expansion ratio and microstructure were evaluated for treated samples and compared with untreated samples. The microstructure of the treated brown rice surface was examined using Scanning Electron Micrograph. Results indicated that the natural morphology of rice bran layer was changed by dynamic mechanical deformation action of ultrasonic waves. This led to improve the cooking quality and reduce cooking time of brown rice. The optimum cooking time of treated brown rice ranged from 24 to $28 \mathrm{~min}$ and from 22 to $24 \mathrm{~min}$ at water temperature of 25 and $40^{\circ} \mathrm{C}$, respectively. Meanwhile the optimum cooking time of white rice and untreated brown rice were 22 and $48 \mathrm{~min}$, respectively. High correlations were found between the cooking time and cooked rice percentage under tested conditions. It has been concluded that ultrasonic treatment could be used to shorten the cooking time and improve cooking properties and quality of brown rice.
\end{abstract}

Keywords: Ultrasonic; Brown rice; Cooking properties; Quality; Cooking time

\section{INTRODUCTION}

7 here is a growing attitude of increased consumption of brown rice due to the health benefits of rice bran layer and its components such as proteins, fats, vitamins, fibers and minerals (Muramatsu et al., 2006). Consequently, brown rice is more nutritious than white or milled rice.

* Lecturer of Agric. Eng. Dept., Fac. of Agric., Suez-Canal Univ., 41522 Ismailia, Egypt. 
However, rice bran layer on brown rice acts as a significant barrier for water absorption during cooking, which results in a prolonged cooking time and limiting the brown rice consumption. Therefore, there is a great need to develop a quick cooking method to reduce cooking time of brown rice and improve its quality. This should lead to maximize the market value of rice by reducing losses and energy use during the milling process.

Milling or polishing of rough rice is the most energy intensive process. Furthermore, in over-milled rice, both the total and whole-grain milling yields are reduced, with a subsequent loss in market value (Kshirod, 2011). The proteins, fats, vitamins, and minerals are concentrated in the germ and outer layer of the starchy endosperm (bran layer) and these are removed in course of milling operation, this reducing the nutritive value of the rice. Moreover, increase in degree of milling reduces the total yield, head yield and increases energy consumption in milling operation (Mutters and Thompson, 2009). To avoid the drawbacks of milling process, several methods have been studied or developed by researchers to reduce cooking time of brown rice to enhance the brown rice consumption.

Partial milling has been used commercially to emphasize on removal of minimum bran from the milled rice to have the acceptable cooking qualities including, minimum cooking time, higher water uptake ratio, length expansion ratio and volume expansion ratio. However, partial milling causes loss of nutrients and integrity of rice bran (Champagne et al., 1990 and Mohapatra and Bal, 2006). Heating and cooling treatments of brown rice before cooking have been used to improve the water absorption during cooking process. The sudden change in temperature can cause fissures in endosperm and improve water uptake of brown rice. The disadvantage of this method is low quality appearance due to breakage of brown rice during cooking (Han and Lim, 2009). Also, enzymatic treatment has been investigated for performing the cellulose degradation in rice bran to improve the bran layer permeability and enhance the water absorption during cooking. The necessity to inactivate the enzyme after treatment makes this method so complicated (Zhang and Zeng, 2006 and Mithu et al., 2008). Hydration using water 
and heat has been studied to reduce cooking time, but the cooked rice taste and texture may not be acceptable due to improper gelatinization (Douglas, 1976 and Afif et al., 1992). Based on aforementioned facts, there is a great need to develop new processing methods for improving the quality and cooking characteristics of brown rice.

Ultrasonic techniques have promising potentials to be used for many food processing applications for both the analysis and modification of foods (Shoh 1988; Floros and Liang, 1994; McClements, 1995; Povey and Mason, 1998; Mulet et al., 1999 and Knorr et al., 2004). Ultrasonic waves ranging from $10 \mathrm{kHz}$ to $1 \mathrm{MHz}$ are relevant for biological and chemical applications (Chung et al., 2002). One of the most important advantages of the ultrasonic technique is that the nondestructive phase transitions in density, elastic and morphological properties can be achieved based on the acoustic response of treated materials. Ultrasonic treatment was found to be effective for conducting degradation for cellulose material by changing the morphology of cellulose fibers (Zhang et al., 2005). Mason and Paniwnyk (1996) mentioned that some destruction of the surface occurred when the rice grains in water were subjected to sonication. Also, Gough and Pybus (1971) reported that changes in rice starch properties observed when the starch was kept in sufficient water above the glass transition temperature and below the gelatinization temperature. Ultrasonic treatments may change the starch and protein structure, thus will improve the rice cooking quality. Despite aforementioned promising features of ultrasonic technology, limited reports are available regarding the potential application of this technology for developing quick cooking method for brown rice. To design an efficient ultrasonic treatment system for brown rice, it is important to delineate the effect of sonication process on quality and cooking properties of brown rice. Therefore, the objective of this study was to (1) investigate the effect of ultrasonic treatments on microstructure, water uptake ratio, volume expansion and length expansion ratios of brown rice, (2) evaluate dissolved materials of brown rice under ultrasonic treatment and (3) develop regression models to predict cooked rice percentage and optimum cooking time of brown rice under the tested conditions. 


\section{MATERIALS AND METHODS}

\section{Preparation of Samples}

Rough rice sample of medium grain variety M202, obtained from Farmer's Rice cooperative (West Sacramento, CA, USA), was used for conducting this research. The rough rice sample had an initial moisture content of $12.0 \pm$ $0.2 \%(\mathrm{wb})$ which was determined by the air oven method of $130^{\circ} \mathrm{C}$ for $24 \mathrm{~h}$ (ASAE, 1995). The sample was dehusked using Yamamoto Husker (FC-2K) to produce brown rice. Then the brown rice sample was split into two large samples. One of them was used for brown rice tests. Foreign substances, damaged kernels, and immature kernels were removed manually from the brown rice sample. The other one was milled using Yamamoto Rice Mill (VP-222N, Yamamoto Co. Ltd., Japan) to produce white rice. It was milled four times to achieve the well milled rice as defined by the Federal Grain Inspection Service (USDA FGIS, 1994). For the first and second times, the settings of throughput and whitening were 1 and 5, respectively. For the third and fourth times, the settings were 1 and 4, respectively. The whiteness index (WI) and milling degree (MD) of white rice were determined using a milling meter (MM1D, Satake, Hiroshima, Japan). Before measuring the whiteness, the milling meter was calibrated with three colored references: white, brown and black, representing standard color values of $85.8,0.8$, and 1.6 , respectively.

\section{Ultrasonic Treatment}

To investigate the effect of ultrasonic treatment on cooking characteristics of brown rice, the samples were ultrasonically treated using a sonicator (Advanced Sonic Processing Systems, Oxford, CT) at frequency of $16 \mathrm{kHz}$ with a power of $2000 \mathrm{~W}$ for four durations, $15,30,45$, and $60 \mathrm{~min}$ as shown in Plate (1) and Fig. (1) at the Food Processing Laboratory in the Department of Biological and Agricultural Engineering, University of California, Davis, USA.

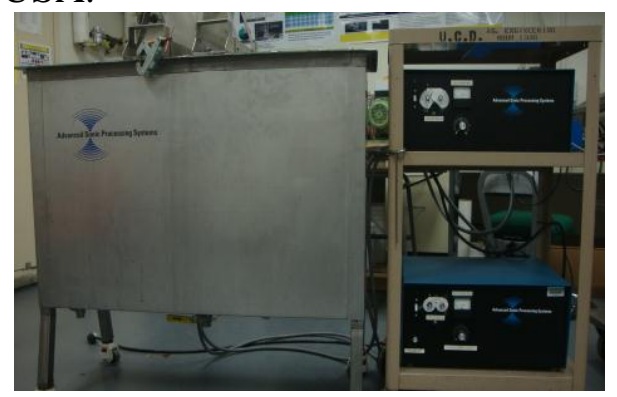

Plate (1): Advanced sonic processing system. 


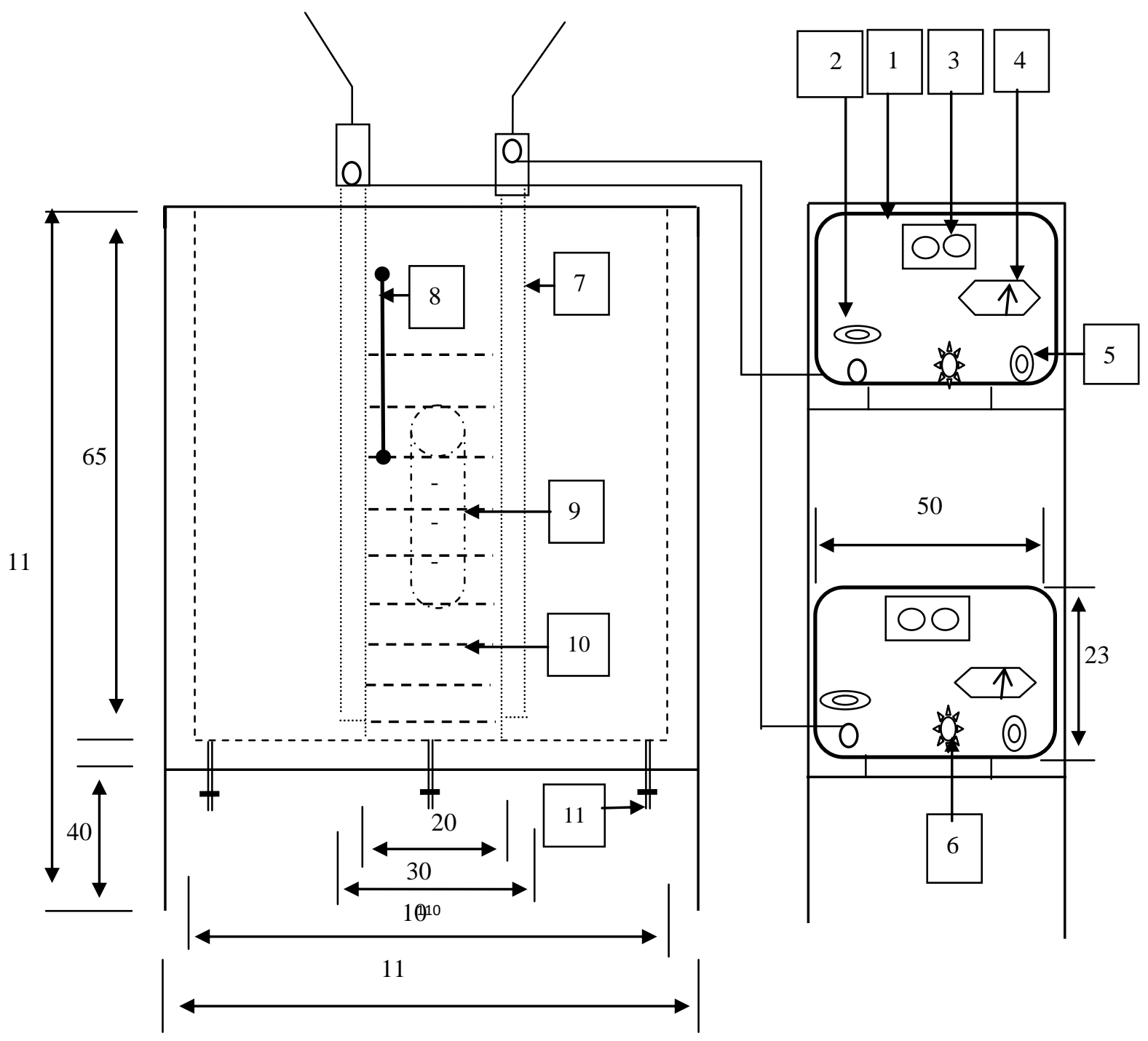

Fig. (1): Schematic diagram representing ultrasonic unit parts: (1)Transducer; (2) Sweep frequency bandwidth; (3) On/Off switch pulsed operation; (4) Ultrasonic power; (5) Electrical supply; (6) Ultrasonic power control; (7) Ultrasonic generator; (8) Thermometer; (9) Rice sample; (10) Water and (11) Water draining valve 
During ultrasonic treatment, the temperature of water in the sonicator chamber was kept at 25 and $40^{\circ} \mathrm{C}$. The water temperature during treatment was kept at targeted constant degree by adding ice to the sonicator chamber when it was necessary. For each ultrasonic treatment, a 500g brown rice sample in a wire bag ( $30 \mathrm{~cm}$ long $\mathrm{x} 20 \mathrm{~cm}$ wide) was immersed in water in the sonicator chamber. After the treatment, the bag with brown rice was removed from the treatment camber and the rice was drained for $1 \mathrm{~min}$ before spreading on a glass plate at room temperature for $10 \mathrm{~min}$ to allow the surface water to evaporate. The treated samples were dried with air at temperatures of $35^{\circ} \mathrm{C}$ to achieve the original MC of untreated brown rice.

\section{Evaluation of Cooking Characteristics}

To investigate the brown rice cooking characteristics after ultrasonic treatments, optimum cooking time, water uptake ratio, length expansion ratio and volume expansion ratio, samples were evaluated and compared with the untreated and white rice samples.

\subsection{Optimum Cooking Time}

The optimum cooking time was determined using the glass plate-white center method (Juliano and Bechtel 1985). In a $50 \mathrm{ml}$ beaker, $25 \mathrm{ml}$ distilled water was boiled $\left(98-100^{\circ} \mathrm{C}\right)$ using a stirring hotplate (Fisher Scientific, CAT SH-heater) and then $5 \mathrm{~g}$ (>100 kernels) brown rice were placed into the boiling water and stirred with a glass rod to ensure even wetting of the kernel surface. After cooking for a specific time (10 minutes), 15 rice kernels were taken out of the beaker and placed in a stainless steel strainer and cooled by running tap water. Then each kernel was pressed using a glass plate against a black background to examine whether the rice kernel has been fully cooked. The fully cooked rice should not show any opaque or uncooked center. The tests were conducted at various cooking times at 2-min intervals until the opaque cores or uncooked centers in all kernels disappeared. The rice was then allowed to simmer for another $2 \mathrm{~min}$ to ensure that it is well cooked. The time was then recorded as the optimal cooking time for the tested rice sample. The test was replicated three times for each specific cooking time. 


\subsection{Water uptake, Volume Expansion and Length Expansion Ratios}

Water uptake ratio, volume expansion ratio and length expansion ratio of rice samples, were determined by cooking $1 \mathrm{~g}$ of the rice sample in $15 \mathrm{ml}$ boiling water, till their optimum cooking times. The water uptake ratio was calculated as the ratio of water absorbed during cooking to uncooked rice weight. The sample weights were measured using an electronic balance with an accuracy of 0.01g (Model No.602, Denver Instrument Co., Arvada, CO). Then the water up take ratio (WUR) was determined using Eq. (1).

$$
W U R=\frac{W C R-W U C R}{W U C R} \times 100
$$

Where: WCR is weight of cooked rice in g, WUCR is weight of uncooked rice in $\mathrm{g}$. The ratio of the initial and final volumes of rice when optimally cooked was referred to volume expansion ratio (VER). The initial and final volumes of rice were determined by volume displacement method and Eq. (2) was used to calculate VER.

$$
V E R=\frac{I V}{F V} \times 100
$$

Where: FV is final volume in $\mathrm{mm}^{3}$, IV is initial volume in $\mathrm{mm}^{3}$. The ratio of the initial and final lengths of rice when optimally cooked was referred to length expansion ratio (LER). The initial and final lengths of rice were determined by Electronic Digital Caliper (1.55 v) and Eq. (3) was used to calculate LER.

$$
L E R=\frac{I L}{F L} \times 100
$$

Where: FL is final length in $\mathrm{mm}$, IL is initial length in $\mathrm{mm}$. Dissolved materials in treating water during ultrasonic treatment were determined by drying the cooking water left in the beaker at $105^{\circ} \mathrm{C}$ for $12 \mathrm{hr}$ and expressed as a percentage of uncooked rice based on dry weight. All aforementioned measurements were conducted in triplicate. 


\section{Microstructure of Treated Brown Rice}

To examine the effect of ultrasonic treatment on the microstructures of brown rice kernels, the scanning electron microscopy (SEM) was used to observe the microstructures of kernel surfaces of different treated rice. The kernels were treated according to the method reported by Zhou et al. (2009). Then they were dried completely under low pressure and then the surface was sputter-coated with gold and observed by scanning electron microscopy (The equipment was scanning electron microscope (Hitachi S-4700, Tokyo, Japan).

\section{Statistical Analysis}

The Sigma Stat software (version 2.0, Jandel Corporation, San Rafael, CA) was used to carry out a multiple comparison procedures and develop regression models between the cooking time and cooked rice percentage to determine optimum cooking time of treated brown rice. This prediction is crucial to optimize the ultrasonic treatment to achieve optimum cooking time for brown rice under the tested condition ranges.

\section{Microstructure of Rice Kernels}

\section{RESULTS AND DISCUSSION}

Scanning electron microscopy (SEM) images of untreated and treated brown and white rice are shown in Fig. (2). The SEM clearly showed that the microstructures of treated and untreated brown rice and white rice were different. It can be seen from Fig. (2B) that the natural morphology of rice bran layer of the treated brown rice was changed by ultrasonic treatment. Whereas, the bran surface of untreated brown rice was compact and had a natural morphology structure. But, the smooth structure of white rice surface facilitates water penetration during cooking process. Moreover, cavitations effect of ultrasonic waves made changes in microstructure of the treated brown rice by forming some crakes in the surface. Thus, ultrasonic treatment could modify the surface structures of brown rice which resulted in increased water uptake during cooking and reduced cooking time. These results are in agreement with those reported by Cui et al. (2010). It is important to notice that the ultrasonic treatment did not significantly change crude fibber, starch, protein, fat, and vitamin contents of treated brown compared to regular brown rice. However, milling, even partial milling, significantly reduced the vitamin and crude fiber contents 
due to removal of bran layer and embryo, resulting in fewer nutrients and health benefits for human consumption as reported by (El-kholy, 2008).

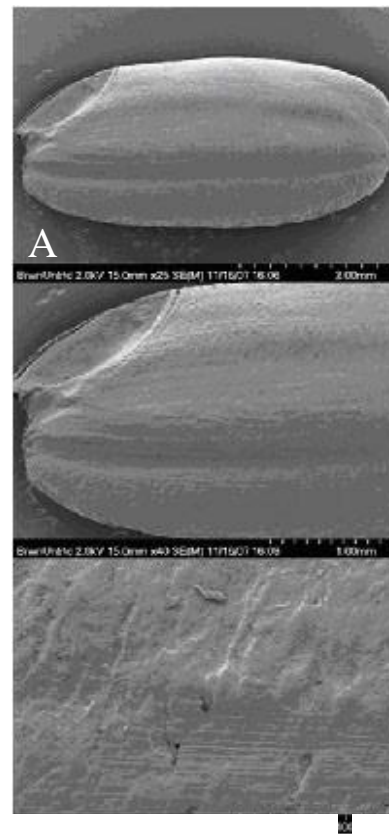

Untreated brown
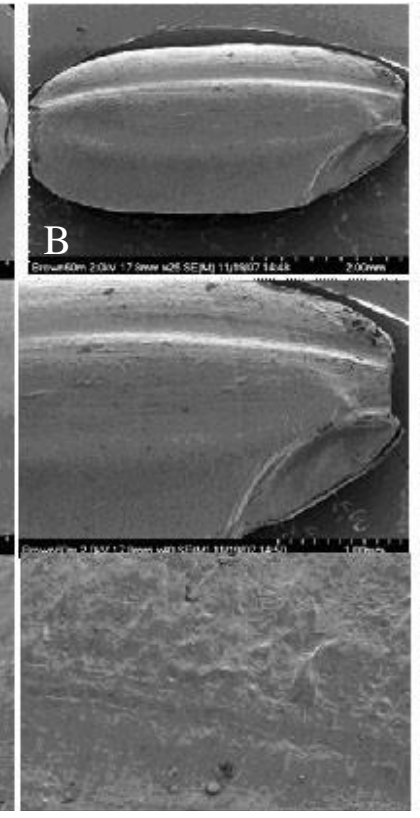

Treated brown rice
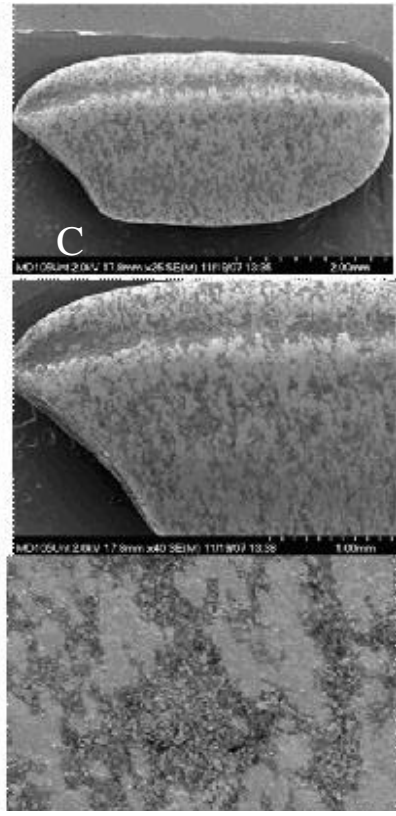

White rice

Fig. (2): Scanning electron microscopy photos of brown and white rice surfaces. $A$ : untreated brown rice; $B$ : treated brown rice (water temperature, $2^{\circ} \mathrm{C}$ and ultrasonic time $60 \mathrm{~min}$ ) and $\mathrm{C}$ : white rice.

\section{Effect of Ultrasonic Treatment on Cooking Characteristics}

The cooking characteristics of ultrasonic treated brown rice were evaluated in terms of optimum cooking time, water uptake ratio, and volume and length expansion ratios.

\subsection{Optimum Cooking Time}

The results indicated that the optimum cooking time for treated brown rice dramatically decreased with ultrasonic treatments compared to untreated brown rice. For instance, when the brown rice samples were treated with ultrasonic at water temperature of $25^{\circ} \mathrm{C}$, optimum cooking time values were $28,26,26$ and 24 min for treatment durations of 15, 30, 
45 and $60 \mathrm{~min}$, respectively (Fig. 3a). The optimum cooking time of white rice and untreated brown rice were 22 and $48 \mathrm{~min}$, respectively. This means that optimum cooking time of ultrasonic treated brown rice decreased from $48 \mathrm{~min}$ to $28,26,26$ and $24 \mathrm{~min}$ for treatment durations of 15, 30, 45 and $60 \mathrm{~min}$, respectively. Also, when the brown rice samples were treated with ultrasonic at water temperature of $40^{\circ} \mathrm{C}$, optimum cooking time values were 24, 24, 24 and $22 \mathrm{~min}$ for treatment durations of 15, 30, 45 and $60 \mathrm{~min}$, respectively (Fig. 3b). This means that by increasing the water temperature form $25^{\circ} \mathrm{C}$ to $40^{\circ} \mathrm{C}$, the optimum cooking time of brown rice slightly decreased form 28, 26, 26 and $24 \mathrm{~min}$ to $24,24,24$ and $22 \mathrm{~min}$ for treatment durations of 15, 30, 45 and $60 \mathrm{~min}$, respectively. Since, optimal cooking time is dependent on the surface area conditions of the rice grain (Juliano and Perez 1983; Kshirod, 2011), the changes in rice bran microstructure made by ultrasonic treatment might improve the water absorption and reduced cooking time. Additionally, high correlations were found between cooking time and cooked rice percentage under tested ultrasonic treatment ranges and water temperatures. Regression models were developed to predict cooked rice percentage and determine optimum cooking time which equal to $100 \%$ of cooked rice percentage under different test conditions as shown in Table (1).

To illustrate the accuracy of predicting cooked rice percentage and optimum cooking time, the differences between predicted and observed cooked rice percentages at optimum cooking time under tested water temperatures and ultrasonic treatment times are shown in Table (2). It is important to notice that the maximum difference was less than $2.8 \%$ and it was positive which mean that all predicted cooked rice percentages were more than $100 \%$. Optimum cooking time was determined at $100 \%$ of cooked brown rice kernels. 


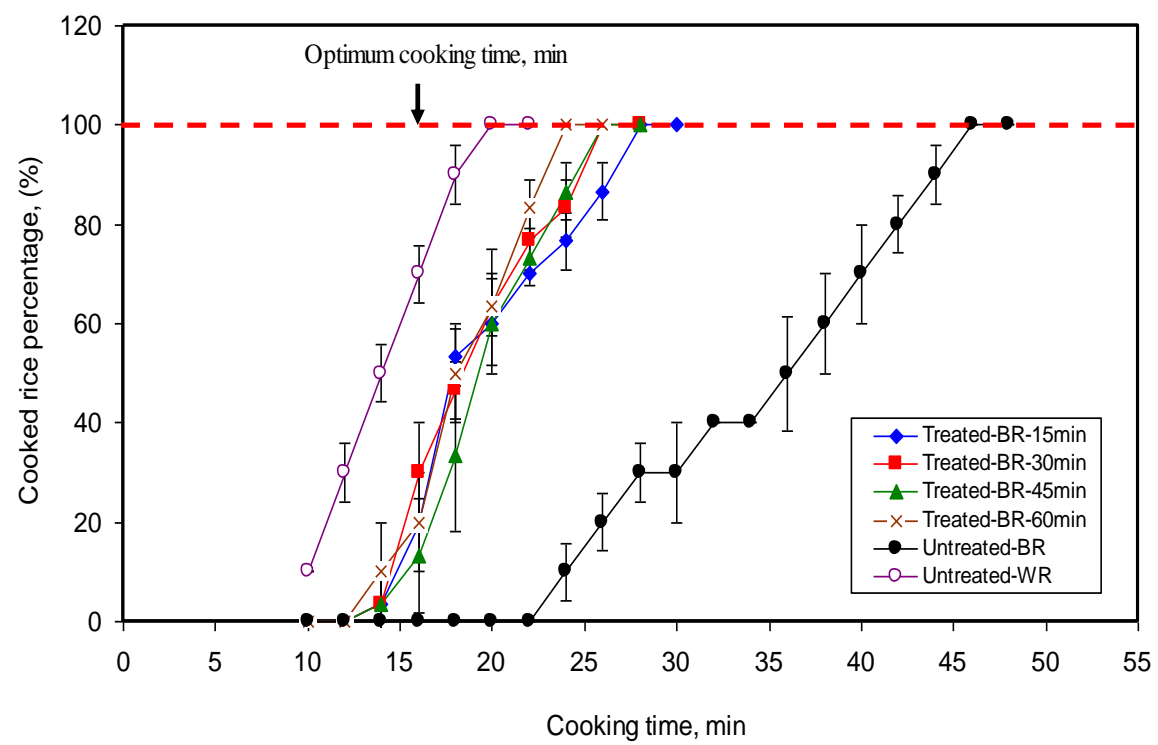

(a)

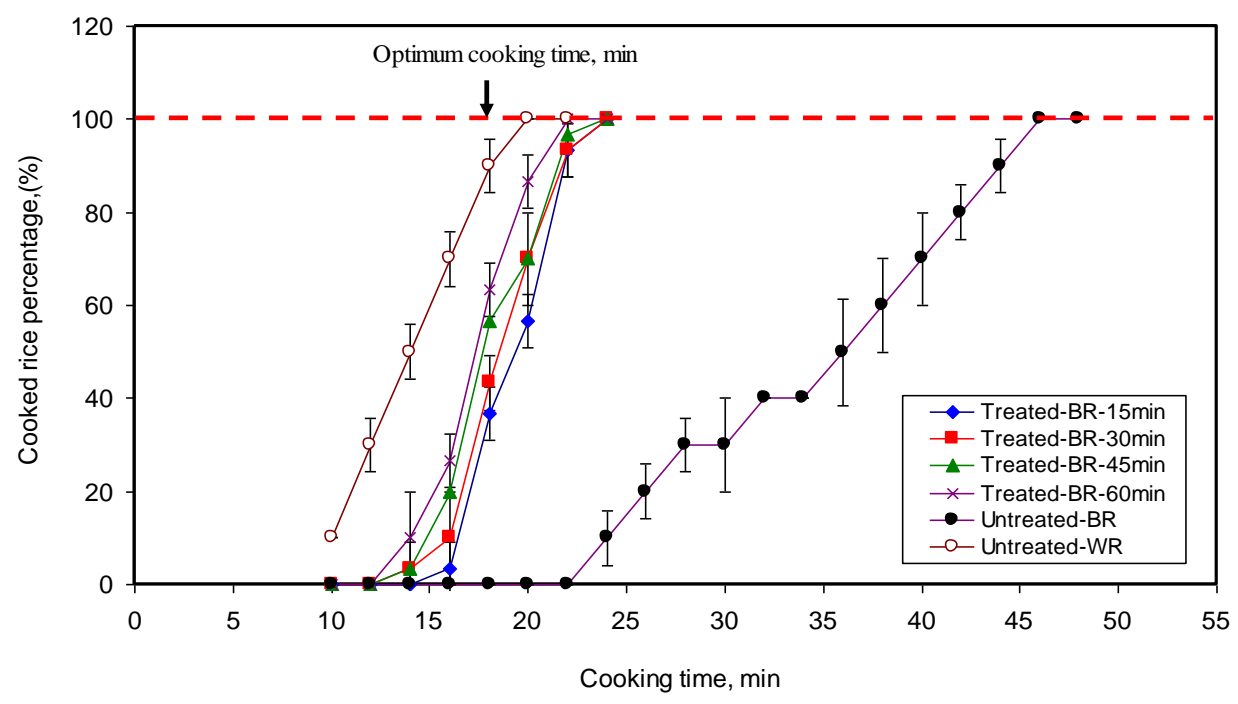

(b)

Fig. (3): Effect of ultrasonic treatment durations on optimum cooking time of brown rice at water temperature of (a) $25^{\circ} \mathrm{C}$, (b) 40 ${ }^{\circ} \mathrm{C}$. (BR: brown rice, WR: White rice). 
Table (1): Regression equations for cooking time (CT) and cooked brown rice percentage (CRP) under different tested water temperatures and ultrasonic treatment times.

\begin{tabular}{|c|c|c|c|c|}
\hline $\begin{array}{c}\text { Water } \\
\text { temperature } \\
\left({ }^{\circ} \mathbf{C}\right)\end{array}$ & $\begin{array}{l}\text { Ultrasonic treatment } \\
\text { time (min) }\end{array}$ & Model & $\mathbf{R}^{2}$ & SEE \\
\hline \multirow{4}{*}{$x_{10}$} & 15 & $\mathrm{CRP}=5.8182 \mathrm{CT}-64.545$ & 0.95 & 1.4 \\
\hline & 30 & $\mathrm{CRP}=6.5354 \mathrm{CT}-73.838$ & 0.97 & 1.1 \\
\hline & 45 & $\mathrm{CRP}=3.7374 \mathrm{CT}-81.010$ & 0.95 & 1.4 \\
\hline & 60 & $\mathrm{CRP}=7.4167 \mathrm{CT}-86.093$ & 0.96 & 1.2 \\
\hline \multirow{4}{*}{40} & 15 & CRP $=8.1548 \mathrm{CT}-102.38$ & 0.90 & 1.7 \\
\hline & 30 & $\mathrm{CRP}=8.3333 \mathrm{CT}-101.67$ & 0.91 & 1.6 \\
\hline & 45 & $C R P=8.4524 C T-100.36$ & 0.93 & 1.5 \\
\hline & 60 & $\mathrm{CRP}=8.7302 \mathrm{CT}-100.08$ & 0.94 & 1.4 \\
\hline
\end{tabular}

SEE: Standard error of estimate.

Table (2). Differences between observed and predicted cooked rice percentages at optimum cooking time under different tested water temperatures and ultrasonic treatment times.

\begin{tabular}{ccc}
\hline $\begin{array}{c}\text { Water } \\
\text { temperature } \\
\left({ }^{\circ} \mathrm{C}\right)\end{array}$ & $\begin{array}{c}\text { Ultrasonic treatment } \\
\text { time (min) }\end{array}$ & $\begin{array}{c}\text { Difference between observed and predicted } \\
\text { cooked rice percentage }(\%)\end{array}$ \\
\hline & 15 & 1.6 \\
25 & 30 & 1.5 \\
& 45 & 2.1 \\
& 60 & 1.7 \\
\hline \multirow{3}{*}{40} & 15 & 2.8 \\
& 30 & 2.6 \\
& 45 & 2.4 \\
\hline
\end{tabular}

\subsection{Water uptake ratio}

The results showed that water uptake ratio significantly $(\mathrm{p}<0.05)$ increased with increase of ultrasonic treatment duration. For instance, water uptake ratios of brown rice treated at water temperature of $25^{\circ} \mathrm{C}$, were $1.33,1.40,1.70$ and 1.75 for treatment durations of $15,30,45$ and $60 \mathrm{~min}$, respectively compared to water uptake ratios of 2.05 and 0.95 for white rice (WR) and untreated brown rice (BR) (Fig. 4a). Water uptake ratios of treated brown rice at water temperature of $40{ }^{\circ} \mathrm{C}$ were 1.34 , 1.42, 1.73 and 1.80 for treatment durations of $15,30,45$ and $60 \mathrm{~min}$, respectively (Fig. 4b). This means that the ultrasonic treatment improved 
water up take ratio of the treated brown rice compared to the untreated brown rice, which is consistent with the results of optimum cooking time. Improved water uptake ratio of treated brown rice may due to dynamic mechanical deformation and increased permeability caused by the propagation of ultrasonic waves at treated rice surface (Imad and John 2006).

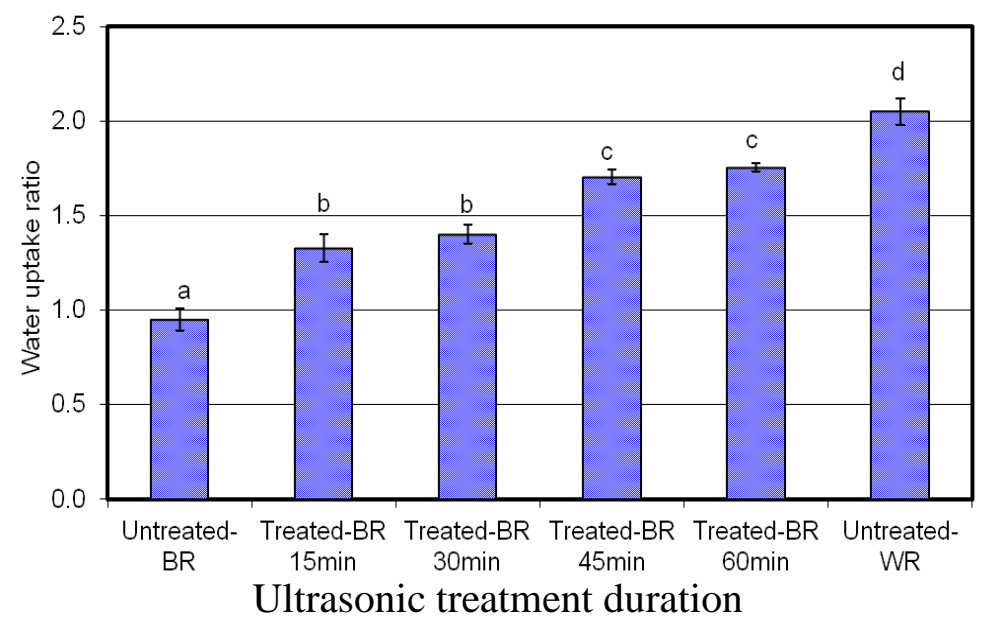

(a)

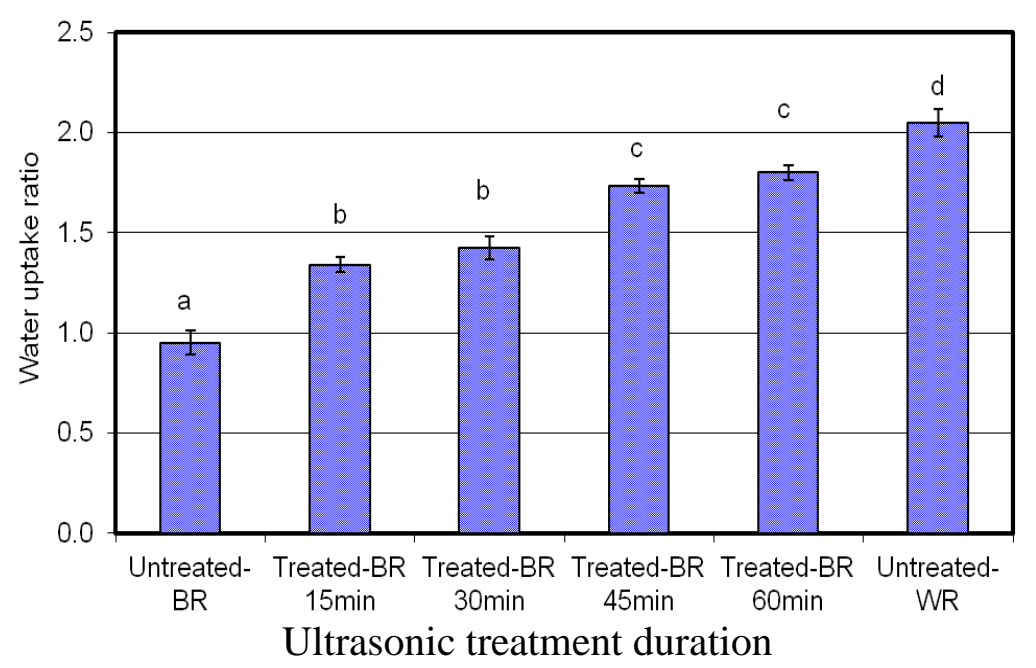

(b)

Fig. (4): Water uptake ratio of brown rice under different ultrasonic treatment durations at water temperature of (a) $25^{\circ} \mathrm{C}$, (b) $40^{\circ} \mathrm{C}$. BR: brown rice, WR: White rice. Values with same letter were not significantly different at $\mathbf{p}<0.05$. 


\subsection{Volume and Length Expansion Ratios}

The results of volume and length expansion ratios are shown in Table (3). The volume expansion ratio increased with increase of ultrasonic treatment duration. For example, volume expansion ratios of treated brown rice at water temperature of $25^{\circ} \mathrm{C}$ were $0.97,1.75,1.84$ and 2.33 for treatment durations of 15, 30, 45 and $60 \mathrm{~min}$, respectively, which are significantly (p $<0.05$ ) higher than the volume expansion ratio of 0.45 for untreated brown rice. There was no significant difference at $p<0.05$ between volume expansion of treated brown rice and white rice. Volume expansion ratios of treated brown rice at water temperature of $40{ }^{\circ} \mathrm{C}$ were $1.08,1.79,1.86$ and 2.38 for treatment durations of $15,30,45$ and $60 \mathrm{~min}$, respectively. This means that the ultrasonic treatment had positive effect on the volume expansion ratio and improved the capacity of starch granule to absorb water and expanded compared to untreated brown rice which may improve the cooking prosperities of brown rice.

Length expansion ratios of treated brown rice at water temperature of $25^{\circ} \mathrm{C}$ were $0.38,0.39,0.40$ and 0.39 for treatment durations of $15,30,45$ and 60 min, respectively compared to length expansion ratios of 0.48 and 0.23 for white rice and untreated brown rice (Table 3). Also, length expansion ratios of treated brown rice at water temperature of $40{ }^{\circ} \mathrm{C}$ were $0.38,0.40$, 0.40 and 0.41 for treatment durations of 15, 30, 45 and $60 \mathrm{~min}$, respectively. There was no significant difference at $(\mathrm{p}<0.05)$ in length expansion between tested rice kernels. This means that ultrasonic treatment duration had little effect on length expansion ratio. This can be explained by the fact that ultrasonic treatment improved the capacity of starch granule to absorb water and expanded in all orientations rather than the liner expansion. 
PROCESS ENGINEERING

Table (3): Average values and standard deviations of volume and length expansion ratios of tested rice kernels.

\begin{tabular}{cccc}
\hline $\begin{array}{c}\text { Water } \\
\text { temperature } \\
\left({ }^{\circ} \mathrm{C}\right)\end{array}$ & $\begin{array}{c}\text { Ultrasonic treatment } \\
\text { time (min) }\end{array}$ & $\begin{array}{c}\text { Volume } \\
\text { expansion } \\
\text { ratio }\end{array}$ & $\begin{array}{c}\text { Length } \\
\text { expansion ratio }\end{array}$ \\
\hline \multirow{2}{*}{25} & 15 & $0.97 \pm 0.14^{\mathrm{a}}$ & $0.38 \pm 0.07^{\mathrm{a}}$ \\
& 30 & $1.75 \pm 0.15^{\mathrm{b}}$ & $0.39 \pm 0.09^{\mathrm{a}}$ \\
& 45 & $1.84 \pm 0.40^{\mathrm{b}}$ & $0.40 \pm 0.17^{\mathrm{a}}$ \\
& 60 & $2.33 \pm 0.58^{\mathrm{b}}$ & $0.39 \pm 0.19^{\mathrm{a}}$ \\
\hline 40 & 15 & $1.08 \pm 0.15^{\mathrm{ab}}$ & $0.38 \pm 0.40^{\mathrm{a}}$ \\
& 30 & $1.79 \pm 0.38^{\mathrm{b}}$ & $0.40 \pm 0.08^{\mathrm{a}}$ \\
& 45 & $1.86 \pm 0.05^{\mathrm{b}}$ & $0.40 \pm 0.08^{\mathrm{a}}$ \\
& 60 & $2.38 \pm 0.54^{\mathrm{b}}$ & $0.41 \pm 0.08^{\mathrm{a}}$ \\
\hline & White rice & $2.90 \pm 0.40^{\mathrm{b}}$ & $0.48 \pm 0.15^{\mathrm{a}}$ \\
\hline
\end{tabular}

Superscript letters indicate that averages with same letters designation in each column are not significantly different at $\mathrm{p}<0.05$.

\section{Dissolved Solids}

The relationship between dissolved solids in water and ultrasonic treatment duration for brown rice and white rice is shown in Fig. (5). In general, brown rice had less dissolved solids compared to white rice. Also, dissolved solids increased with increase of treatment duration. For instance, when the brown rice samples were treated at water temperature of $25^{\circ} \mathrm{C}$, dissolved solids were $0.010,0.012,0.024$ and $0.022 \mathrm{~g}$ per gram of brown rice for ultrasonic treatment durations of 15, 30, 45 and $60 \mathrm{~min}$, respectively. When the white rice samples were treated at water temperature of $25^{\circ} \mathrm{C}$, dissolved solids were $0.043,0.055,0.064$ and $0.062 \mathrm{~g}$ per gram for ultrasonic treatment durations of 15, 30, 45 and $60 \mathrm{~min}$, respectively. Dissolved solids at water temperature of $40^{\circ} \mathrm{C}$ were 0.010 , $0.013,0.026$, and $0.024 \mathrm{~g}$ for brown rice and $0.045,0.058,0.065$, and 0.068 $\mathrm{g}$ for white rice with ultrasonic treatment durations of 15, 30, 45 and 60 min, respectively. This means that the water temperature effect on dissolved solids was not significant, but the dissolved solids increased with the increase of treatment time up to $45 \mathrm{~min}$ and start to slightly decreased at 60 min treatment time. 
Based on obtained results, it can be noticed that the ultrasonic treatment was vital to improve the cooking properties of brown rice and significantly reduce the cooking time. At the same time, it is important to notice that the reported results by Cui et al. (2010) confirmed that ultrasonic treatment had a positive impact on physical and chemical properties of brown rice of medium grain rice variety M202.

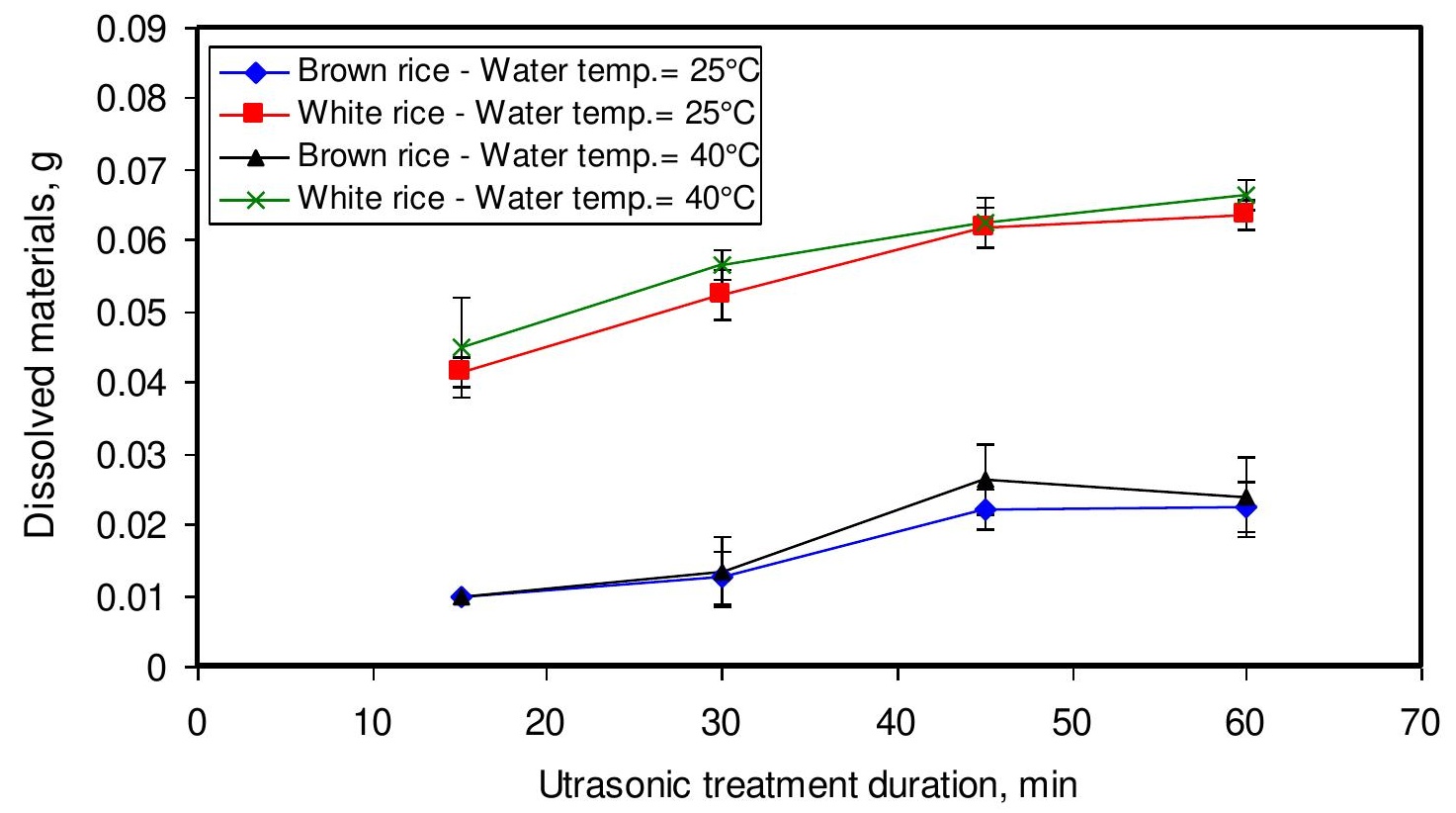

Fig. (5): Relationship between dissolved solids and ultrasonic treatment durations at different water temperatures.

\section{CONCLUSIONS}

This research revealed that ultrasonic treatment can be used as an effective method to reduce the cooking time and enhance the cooking characteristics of brown rice. The optimum cooking time of treated brown rice at water temperature of $25^{\circ} \mathrm{C}$, were $28,26,26$ and 24 min for ultrasonic treatment durations of $15,30,45$ and $60 \mathrm{~min}$, respectively. The corresponding optimum cooking times at water temperature of $40^{\circ} \mathrm{C}$ were $24,24,24$ and $22 \mathrm{~min}$. The optimum cooking time of white rice and untreated brown rice were 22 and $48 \mathrm{~min}$, respectively. High correlations were found between 
the cooking time and cooked rice percentage which are vital to predict the optimum cooking time of rice kernels under the tested conditions. Additionally, ultrasonic wave propagation made changes in microstructure of rice bran layers. This led to allow water to penetrate the rice kernel easily, resulting in an increased water absorption ratio during cooking process and reducing cooking time. Also, the good cooking properties such as volume expansion ratio and reduced dissolved solids were achieved under ultrasonic treatment. These results constitute essential information to design and develop the potential ultrasonic brown rice cookers.

\section{ACKNOWLEDGEMENTS}

The author thanks Farmers' Rice Cooperative, California State, USA and the California Rice Research Board for supplying rice samples. Also, the author appreciates assistance from Department of Biological and Agricultural Engineering, University of California Davis, USA, and Department of Agricultural Engineering, Faculty of Agriculture, Suez Canal University, Ismailia, Egypt for conducting this research.

\section{REFERENCES}

Afif, A. B., Jau, Y. H. and Eugene, S. (1992). Preparation of quick cooking rice. U.S. patent 5089281.

ASAE Standards, (1995). S352.2: 1 Moisture measurementsUngrounded grain seeds Moisture relationships of grains $\left(42^{\text {nd }} e d.\right)$. St. Joseph, MI: ASAE.

Champagne, E. T., Marshall, W. E. and Goynes, W. R. (1990). Effects of degree of milling and lipid removal on starch gelatinization in the brown rice kernel. Cereal Chem. 67, 570-574.

Chung, K. M., Moon, T. W., Kim, H. C. and Kim, J. (2002). Physicochemical properties of sonicated mung bean, potato, and rice starches. Cereal Chem. 79:631-633.

Cui, L., Pan, Z., Yue, T., Atunglulu, G. and Berrios, J. (2010). Effect of ultrasonic treatment of brown rice at different temperatures on cooking properties and quality. Cereal Chem. 78, (5), 403-408. 
Douglas, M. (1976). Process for preparing quick-cooking brown rice and the resulting products. U.S. patent 3959515.

El-kholy, M. M. (2008). Whitening characteristics of different rice varieties using two different types of milling machines. Egypt J. of Agric. Res. 86 (2): 675-694

Floros, J. D. and Liang, H. (1994). Acoustically assisted diffusion through membranes and biomaterials. Food Tech., 48, 79-84.

Gough, B. M. and Pybus, J. N. (1971). Effect on the gelatinization temperature of wheat starch granules of prolonged treatment with water at $50^{\circ} \mathrm{C}$. Starch $23,210-212$.

Han, J. A. and Lim, S.T. (2009). Effect of presoaking on textural, thermal, and digestive properties of cooked brown rice. Cereal Chem. 86,100-105.

Imad, A. F. and John, R. M. (2006). Ultrasonic investigation of wheat starch retrogradation. J. Food Eng. 75, 258-266.

Juliano, B. O. and Bechtel, D. B. (1985). The rice grain and its gross composition. Pages 17-50 in: Rice: Chemistry and Technology, 2nd Ed. AACC International: St. Paul, MN.

Juliano, B. O. and Perez C. M. (1983). Major factors affecting cooked milled rice hardness and cooking time. J Texture Stud, 14, 235-243.

Knorr, D., Zenker, M., Heinz, V. and Lee, D. (2004). Applications and potential of ultrasonic in food processing. Trends in Food Sci. and Technol., 15, 261-266.

Kshirod, R. B. (2011). Rice quality: a guide to rice properties and analysis. Woodhead Publishing, PA, USA, 61-114.

Mason, T. J., Paniwnyk, L. and Lorimer, J. P. (1996). Uses of ultrasound in food technology. Ultrasonics Sonochem. 6,253-260.

McClements, D. J. (1995). Advances in the application of ultrasound in food analysis and processing. Trends in Food Sci.and Technol., 6, 293-299. 
Mithu, D., Gupta, S., Kapoor, V., Banerjee, R. and Bal, S. (2008). Enzymatic polishing of rice-A new processing technology. Food Sci. Technol. 41,2079-2084.

Mohapatra, D. and Bal, S. (2006). Cooking quality and instrumental textural attributes of cooked rice for different milling fractions. J. Food Eng. 73:253-259.

Mulet, A., Benedito, J., Bon, J. and Sanjuan, N. (1999). Low intensity ultrasonics in food technology. Food Sci. and Technol. International, 5, 285-297.

Muramatsu, Y., Tagawa, A., Sakaguchi, E. and Kasai, T. (2006). Water absorption characteristics and volume changes of milled and brown rice during soaking. Cereal Chem. 83:624-631.

Mutters, R. G. and Thompson, J. F. (2009). Rice quality handbook. University of California, Agriculture and Natural Resources, Publication 3514, Oakland, California.

Povey, M. J. W. and Mason, T. J. (1998). Ultrasound in food processing. London: Blackie Academic \& Professional.

Shoh, A. (1988). Industrial applications of ultrasound. In K. S. Suslick (Ed.), Ultrasound, its chemical, physical and biological effects (pp. 97-122). New York: VCH Publishers, Inc.

USDA-FGIS. (1994). Rice Inspection Handbook. Washington, D.C., USDA Agricultural Marketing Service.

Zhang, R. and Zeng, J. (2006). Study on conditions of enzymatic hydrolyzing anti-nutrition factor in brown rice. Food Sci., 27, 262266.

Zhang, Z., Feng, H., Niu, Y. and Eckhoff, S. R. (2005). Starch recovery from degermed corn flour and hominy feed using power ultrasound Cereal Chem. 82,447-449.

Zhou, L., Liangming, C., Ling, J., Zhang W., Liu, L., Xi, L., Zhigang, Z., Shijia, L., Lujun, Z., Jiankang, W. and Jianmin, W. (2009). Fine mapping of the grain chalkiness QTL PGWC-7 in rice (Oryza sativa L.). Theor. Appl. Genet.118,581-590. 


\section{الملخص العربي}

\section{تحسين خواص جودة وطبخ الأرز البني باستخدام الموجات فوق الصوتية}

\section{"رجب خير عبد القادر}

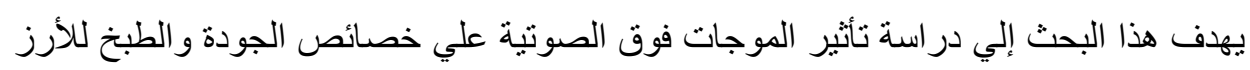

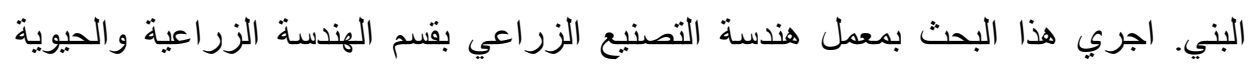

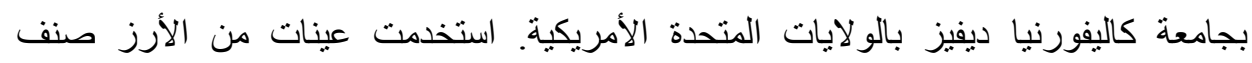

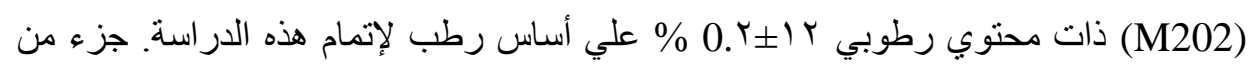

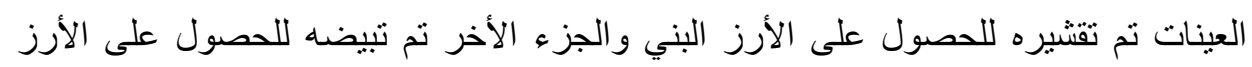

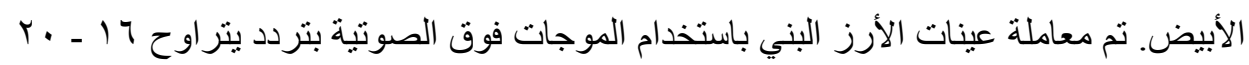

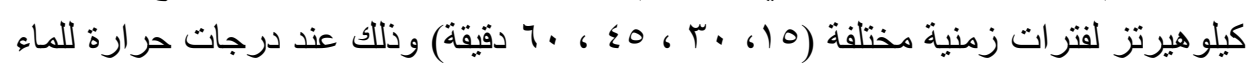

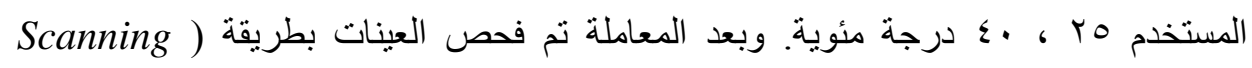
(Electron Micrograph

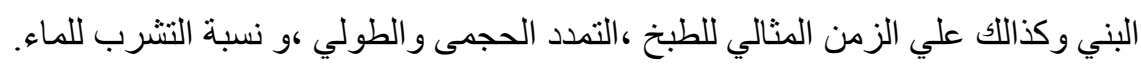

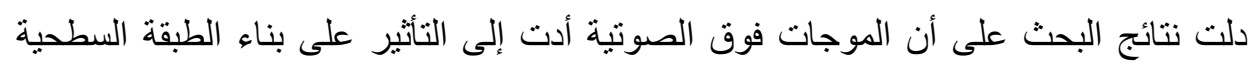

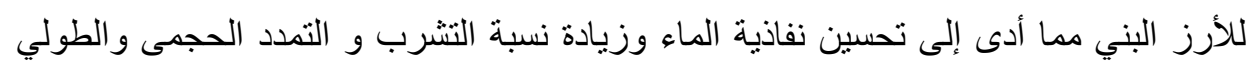

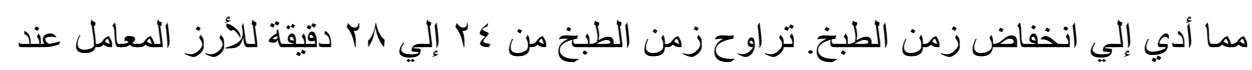

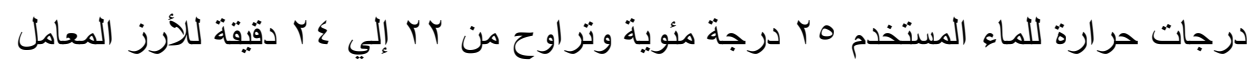

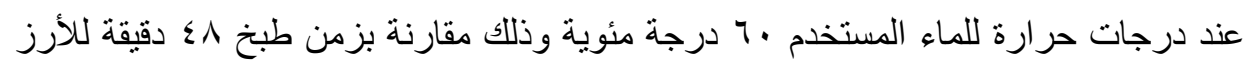

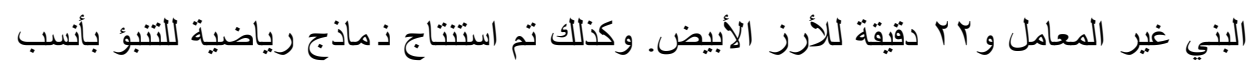

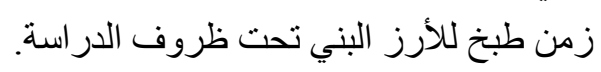

* مدرس بقسم الهندسة الزراعية ـ كلية الزراعة ـ جامعة قناة السويس 